\title{
A Note on the Size of Forward Exchange Rate Bias
}

\author{
Guan Jun Wang ${ }^{1}$ \\ ${ }^{1}$ College of Business Administration, Savannah State University, Savannah, GA, USA \\ Correspondence: Guan Jun Wang, College of Business Administration, Savannah State University, Savannah, \\ GA 31410, USA. Tel: 912-358-3416. E-mail: wangg@ savannahstate.edu
}

Received: June 8, 2015

Accepted: June 23, 2015

Online Published: August 25, 2015

doi:10.5539/ijef.v7n9p237

URL: http://dx.doi.org/10.5539/ijef.v7n9p237

\begin{abstract}
In this short note, we argue that the rejection of forward exchange rate unbiasedness hypothesis (FRUH) does not necessary mean that forward exchange rates have little effect as forecasts of future spot exchange rates as claimed in the literature. Due to symmetric feature of foreign exchange markets, we conjecture the size of forward exchange rate bias should be fairly small. We combine theoretical analysis with the observation of empirical results to validate this conjecture.
\end{abstract}

Keywords: Foreign exchange rate, spot rate, forward exchange rate bias, Jensen's inequality, symmetry

\section{Introduction}

In the past few decades, numerous empirical studies (Fama, 1984; Frenkel \& Froot, 1989; Aggarwal et al., 2009; Sarno et al., 2012, among others) have been conducted to test the forward exchange rate unbiasedness hypothesis (FRUH), that is, whether the forward exchange rates are unbiased estimators of the corresponding future spot rates. Due to the overwhelming rejection of FRUH, it is commonly concluded in the literature (Wu \& Zhang, 1997; Aggarwal et al., 2009, among others) that the forward exchange rates have little effect as forecasts of future spot exchange rates. The empirical rejection of FRUH is also referred to as forward exchange rate bias puzzle in the literature (see Aggarwal et al., 2009, etc). There are numerous studies that attempt to explain this puzzle. Notable recent papers include Verdelhan (2010) who uses the argument of investors' external habit preferences over consumption in both good and bad times and Lustig et al. $(2011,2014)$ who perform a cross-sectional analysis of foreign exchange portfolios to explain the determination of exchange rates. Earlier literatures that attempt to explain the forward exchange rate bias puzzle include Backus et al (1993) and Bekaert (1996).

Despite the fact that there are two forms of exchange rate quotes, direct or indirect-in a direct quote, the exchange rates are quoted as domestic currency per unit of foreign currency, and in an indirect quote, the exchange rates are quoted as foreign currency per unit of domestic currency, and the direct quote is the reciprocal of the indirect quote, the conventional empirical tests mentioned above often only use one type of the two quotations, either direct or indirect, but not the both. In the remaining of this note, we define domestic investors as investors who exchange domestic currency for foreign currency and foreign investors as investors who exchange foreign currency for domestic currency. Siegel (1972) has argued that when foreign exchange market investors are risk neutral, the forward exchange rates are biased estimators of the expected future spot rates. His argument rests on Jensen's inequality using both exchange rate quotations. If we let $F_{t, t+T}$ denote indirect (direct) quote of T-time forward exchange rate at time t, and $S_{t+T}$ indirect (direct) quote of corresponding future spot rate at time $\mathrm{t}+\mathrm{T}$, then $\frac{1}{F_{t, t+T}}$ is the direct (indirect) quote of T-time forward exchange rate at time $\mathrm{t}$, and $\frac{1}{S_{t+T}}$ the direct (indirect) quote of corresponding future spot rate at time $\mathrm{t}+\mathrm{T}$. If we expect $F_{t, t+T}$ to be an unbiased 
estimator of $S_{t+T}$, that is,

$$
F_{t, t+T}=E S_{t+T}
$$

where $\mathrm{E}$ is the expectation operator, then by applying Jensen's Inequality which states that the strictly convex transformation of a mean is less than the mean after convex transformation, to the strictly convex function $f(x)=\frac{1}{x}$, we have:

$$
E \frac{1}{S_{t+T}}>\frac{1}{E S_{t+T}}
$$

Substitute $F_{t, t+T}=\mathrm{E} S_{t+T}$, we have:

$$
E \frac{1}{S_{t+T}}>\frac{1}{F_{t+T}}
$$

Thus we have shown that if forward rates quoted indirectly (directly) are unbiased estimators of future corresponding spot rates quoted indirectly (directly), that is, $F_{t, t+T}=E S_{t+T}$, the same currency pair forward rates quoted directly (indirectly) must be (downward ) biased estimators of future corresponding spot rates quoted directly (indirectly), that is, $E \frac{1}{S_{t+T}}>\frac{1}{F_{t+T}}$. Based on Siege's above argument, the forward exchange rates should not be expected to be unbiased estimators of future corresponding spot rates for both domestic and foreign investors, that is, the rejection of FRUH should not be a puzzle. However, scholars and academicians in international finance seemed to have ignored the Siege's argument, efforts have been continuously made to test the FRUH. The focus of this short note is to assess the size of forward exchange rates bias-the degree of the usefulness of the forward exchange rates in predicting corresponding future spot rates in spite of the rejection of FRUH.

The reminder of this paper is organized as follows. Section 2 further provides our theoretical argument that despite the rejection of FRUH, the size of forward exchange rate bias should be fairly small. Section 3 presents our empirical testing results to validate our theoretical argument. Section 4 discusses implications and concludes.

\section{The Size of Forward Exchange Rate Bias}

Despite siege's argument in early 1970s, two views still prevail in the field of international finance towards whether forward exchange rates are unbiased estimators of corresponding future spot rates, one in fully support of FRUH (see Chiang, 1988, etc.) and one fully opposing the FRUH (see Frenkel ,1981; Aggarwal et al., 2009, etc.). Due to the overwhelming empirical rejection of FRUH, it is commonly concluded in the late literature that the forward exchange rates have little effect as forecasts of future spot exchange rates-the complete rejection of the usefulness of forward exchange rates in predicting future spot rates. We support neither of the views.

As stated in Wystup (2010), "the symmetries of the foreign exchange market are the key feature that distinguishes this market from all others. With EUR-USD exchange rate of 1.25 USD per EUR, there is an equivalent USD-EUR exchange rate of 0.8 EUR per USD, which is just the reciprocal. Any model $S_{t}$ for an exchange rate at time t should guarantee that $\frac{1}{S_{t}}$ is within the same model class." Due to the symmetric feature of foreign exchange markets, we expect participants (investors) on both side of the foreign exchange markets express themselves symmetrically with the objective to maximize their profits. We argue, though we don't expect forward exchange rates to be unbiased estimators of corresponding future spot rates as stated in Siegel 
(1972), we expect them to be close to the corresponding future spot rates. We develop the following Theorem to show that if the forward rate $F_{t+T}$ quoted in an indirect (direct) form is significantly upward biased as estimator of corresponding future spot rate $S_{t}$ for domestic investors (foreign investors), then the same currency pair forward rate quoted in a direct (indirect) form which is $\frac{1}{F_{t+T}}$ would be significantly downward biased as estimator of corresponding future spot rates quoted in a direct (indirect) form for foreign investors (domestic investors), which contradicts the symmetric features of foreign exchange markets.

Theorem: Let $F_{t, t+T}$ denote indirect (direct) quote of T-time forward exchange rate at time $\mathrm{t}$, and $S_{t+T}$ indirect (direct) quote of future spot rate at time $\mathrm{t}+\mathrm{T}$ for domestic investors (foreign investors), and then $\frac{1}{F_{t, t+T}}$ is the direct (indirect) quote of T-time forward exchange rate at time $\mathrm{t}$, and $\frac{1}{S_{t+T}}$ the direct (indirect) quote of future spot rate at time $\mathrm{t}+\mathrm{T}$ for foreign investors (domestic investors). Let $\delta_{D(F)}=\frac{F_{t, t+T}-E S_{t+T}}{F_{t+T}}$ denote the size of forward exchange rate bias for domestic investors (foreign investors), and let $\delta_{F(D)}=\frac{\frac{1}{F_{t, t+T}}-E \frac{1}{S_{t+T}}}{\frac{1}{F_{t, t+T}}}$ denote the size of forward exchange rate bias for foreign investors (domestic investors). If,

$$
\delta_{D(F)}=\frac{F_{t, t+T}-E S_{t+T}}{F_{t+T}} \geq \mathrm{C}(0<\mathrm{C}<1)
$$

then

$$
\delta_{F(D)}=\frac{\frac{1}{F_{t, t+T}}-E \frac{1}{S_{t+T}}}{\frac{1}{F_{t, t+T}}}<-\frac{C}{1-C}
$$

Proof: Applying Jensen's Inequality to the strictly convex function $f(x)=\frac{1}{x}$, we have

$$
E \frac{1}{S_{t+T}}>\frac{1}{E S_{t+T}}
$$

applying some simple properties of inequality to $\delta_{D(F)}=\frac{F_{t, t+T}-E S_{t+T}}{F_{t, t+T}}>\mathrm{C}(0<\mathrm{C}<1)$, we immediately have

$$
\frac{F_{t, t+T}}{E S_{t+T}}>\frac{1}{1-C}
$$

Applying the above inequalities, we have: 


$$
\delta_{F(D)}=\frac{\frac{1}{F_{t, t+T}}-E \frac{1}{S_{t+T}}}{\frac{1}{F_{t, t+T}}}<\frac{\frac{1}{F_{t, t+T}}-\frac{1}{E S_{t+T}}}{\frac{1}{F_{t, t+T}}}=1-\frac{F_{t, t+T}}{E S_{t+T}}<1-\frac{1}{1-C}=-\frac{C}{1-C}
$$

Thus we have proved the Theorem.

We should notice that the value of $\frac{C}{1-C}$ is greater than $\mathrm{C}$ and increases as $\mathrm{C}$ increases. According to the Theorem, for example, if $F_{t, t+T}$, the indirect (direct) quote of T-time forward exchange rate at time t is $5 \%$ (C-=5\%,) higher than $S_{t+T}$, the indirect (direct) quote of future spot rate at time $\mathrm{t}+\mathrm{T}$ for domestic investors (foreign investors), that is, $\delta_{D(F)} \geq 5 \%$, then $\frac{1}{F_{t, t+T}}$, the direct (indirect) quote of T-time forward exchange rate at time t would be $5.3 \%\left(\frac{C}{1-C} \approx 5.3 \%\right)$ lower than $\frac{1}{S_{t+T}}$, the direct (indirect) quote of future spot rate at time $\mathrm{t}+\mathrm{T}$ for foreign investors (domestic investors), that is, $\delta_{F(D)}<-5.3 \%$. Table 1 shows a sample of the asymmetrical relationship between $\delta_{D(F)}$ and $\delta_{F(D)}$.

Table 1. Asymmetrical relationship between forward exchange rate biases for domestic and foreign investors

\begin{tabular}{cccccc}
\hline C & $2 \%$ & $4 \%$ & $6 \%$ & $8 \%$ & $10 \%$ \\
\hline If $\delta_{D(F)} \geq$ & $2 \%$ & $4 \%$ & $6 \%$ & $8 \%$ & $10 \%$ \\
Then $\delta_{F(D)} \leq$ & $-2.0 \%$ & $-4.2 \%$ & $-6.4 \%$ & $-8.7 \%$ & $-11.1 \%$ \\
\end{tabular}

$\delta_{D(F)}$ denotes the size of forward exchange rate bias for domestic investors (foreign investors), and $\delta_{F(D)}$ denotes the size of forward exchange rate bias for foreign investors (domestic investors).

\section{Empirical Results}

In this section, we present some empirical results to support our conjecture that though forward exchange rates may be biased estimators of corresponding future spot rates, such bias is fairly small.

The dataset used in our empirical study consists of daily frequency observations obtained from Bloomberg of the spot and one month forward exchange rates for three major currencies against US dollar: Euro (EUR), Japanese Yen (JPY) and Canadian Dollar (CAD). Exchange rates are expressed in both direct and indirect forms. The range of the data observations goes from February 1995 to August 2010. Table 2 reports descriptive statistics for the size of forward exchange rate biases for both domestic and foreign investors for three currency pairs. As the results shown in Table 2, the mean value of the biases for all three currency pairs are extremely low $(<0.003$, or $0.3 \%)$ with standard errors less than 0.006 (or $0.6 \%$ ) for both domestic investors and foreign investors. Though the qualitative interpretation of the skewness is complicated, the absolute low value of skewness $(<1)$ indicates that the distribution of the forward exchange rate bias is only moderately skewed from the mean value, and the positive excess kurtosis indicates the distribution of the bias is a "peaked" distribution around mean value. Figure 1 shows the histograms of the forward exchange rate bias for the above three currencies against dollar. Our empirical results strongly support our conjecture and confirm that the size of the forward exchange rate biases are 
fairly small.

Table 2. Descriptive statistics of the size of forward exchange rate bias $\delta_{D}$ and $\delta_{F}$

\begin{tabular}{lcccccc}
\hline & $\mathbf{E U R}\left(\delta_{D}\right)$ & $\mathbf{E U R}\left(\delta_{F}\right)$ & $\mathbf{J P Y}\left(\delta_{D}\right)$ & $\mathbf{J P Y}\left(\delta_{F}\right)$ & $\mathbf{C A D}\left(\delta_{D}\right)$ & $\mathbf{C A D}\left(\boldsymbol{\delta}_{F}\right)$ \\
\hline Mean & -0.000881 & -0.000106 & -0.002952 & 0.001780 & 0.000324 & -0.000624 \\
Standard Error & 0.000574 & 0.000574 & 0.000533 & 0.000540 & 0.000273 & 0.0002706 \\
Median & 0.000484 & -0.000484 & -0.005024 & 0.004999 & 0.000447 & -0.000447 \\
Standard Deviation & 0.031445 & 0.031439 & 0.03396 & 0.034404 & 0.017415 & 0.0172582 \\
Sample Variance & 0.000989 & 0.000988 & 0.001153 & 0.001183 & 0.000303 & 0.0002978 \\
Kurtosis & 0.781951 & 0.979519 & 1.098050 & 1.704252 & 5.41329 & 4.0220007 \\
Skewness & -0.112609 & -0.154767 & 0.359472 & -0.675383 & -0.74391 & 0.4160825 \\
Range & 0.289164 & 0.295450 & 0.279724 & 0.292747 & 0.212981 & 0.2032689 \\
Minimum & -0.144395 & -0.169274 & -0.127322 & -0.179804 & -0.13563 & -0.083839 \\
Maximum & 0.144769 & 0.126175 & 0.152402 & 0.112942 & 0.077355 & 0.1194290 \\
Sum & -2.646268 & -0.318105 & -11.97465 & 7.2232 & 1.315553 & -2.536642 \\
Count & 3004 & 3004 & 4056 & 4056 & 4065 & 4065 \\
Confidence Level (95.0\%) & 0.001125 & 0.001124 & 0.001045 & 0.00105 & 0.000536 & 0.0005306 \\
\hline
\end{tabular}

This table shows the descriptive statistics of the size of forward exchange rate biases. $\delta_{D}$ denotes the bias for domestic investors when exchange rate expressed in an indirect form, that is, the exchange rates are quoted as foreign currency per unit of US dollar, and $\delta_{F}$ denotes the forward exchange rate bias for foreign investors when exchange rate expressed in direct form, that is, the exchange rates are quoted as US dollar per unit of foreign currency. Exchange rate data spanned from February 1995 to August 2010. To match the forward rates and their corresponding future spot rates, some of the data during the period were excluded.

\section{Limitation, Implications and Conclusion}

Our argument rests on investors risk neutrality and foreign exchange market symmetry assumptions. These are reasonable and rational assumptions, but in the real world they may not always hold because financial markets can be full of all types of investors whose preferences over risk and financial behaviors vary with age, net worth and level of financial literacy, just to name a few. Investors' attitudes towards risk can be neutral or averse or loving, though the last type of investors is not common. Investors' financial behavior can be either rational or irrational (Note 1). If majority foreign currency investors are not risk neutral, and investors on each side of foreign currency market don't act symmetrically, then the large forward rate bias should not be a surprise. The empirical testing results presented in this short note are more conformable with both investors risk neutrality and market symmetry assumptions. 

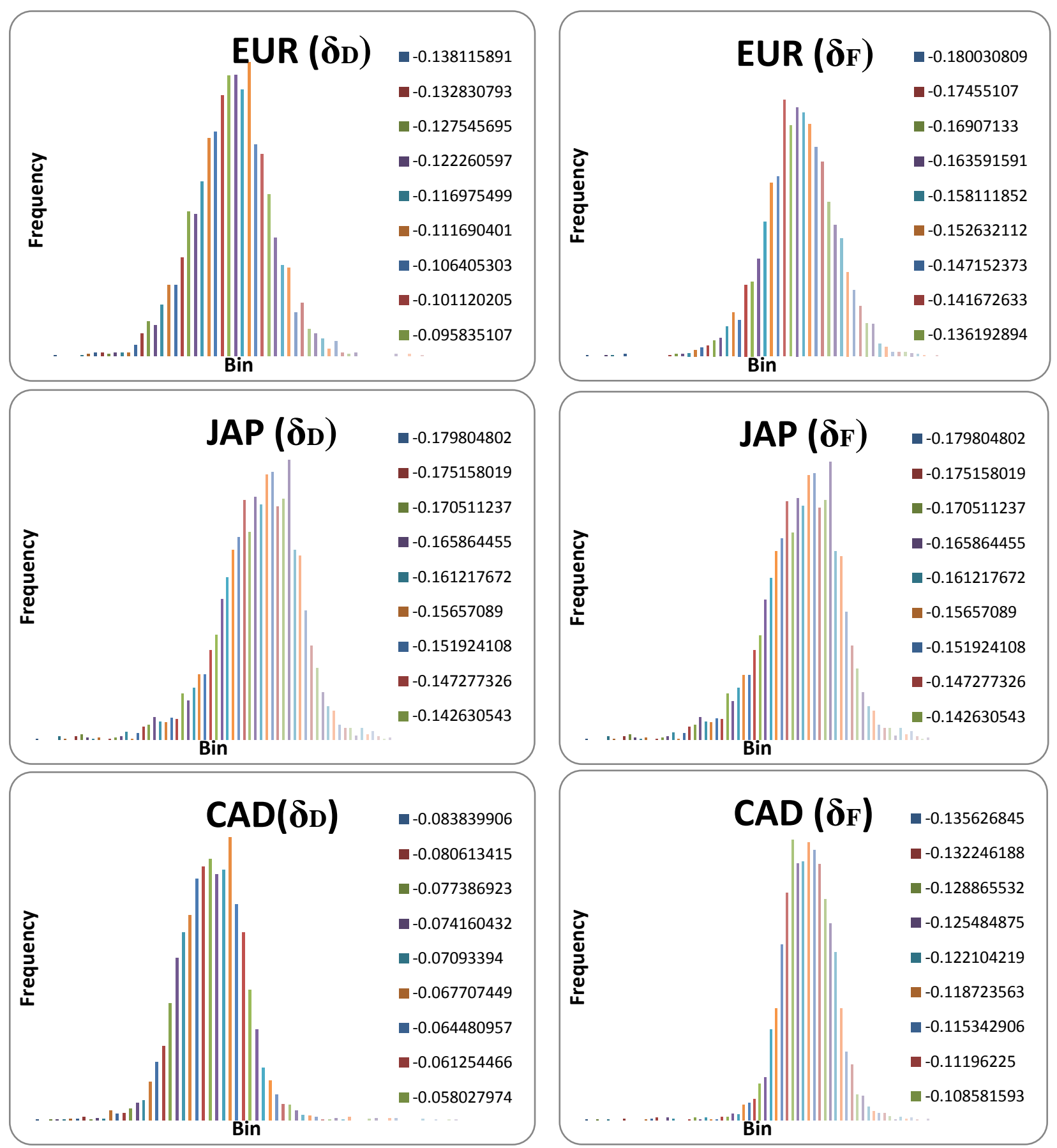

Figure 1. Histograms of the percentage bias of forward exchange rate

Though our empirical tests are limited to one month forward rates and three currency pairs, we believe the size of forward rate for other currency pair is small as well as long as foreign currency market symmetry assumption holds.

In sum, in this short note, we argue though forward exchange rates are biased estimators of corresponding future spot rates, such biases are fairly small. We attribute the small size of forward exchange rate bias to the distinguished symmetric feature of the foreign exchange markets. We provide both theoretical argument and empirical results to support our view. The implication of our finding is that while we reject the forward exchange rate unbiasedness hypothesis, we don't reject the rich information contained in forward exchange rates about corresponding future spot rates. Our conclusion is, though biased, forward exchange rates are good predictors of corresponding future spots rates. 


\section{References}

Aggarwarl, R., Lucey, B., \& Mohanty, S. (2009). The forward exchange rate bias puzzle is persistent: Evidence from stochastic and nonparametric cointegration tests. Financial Review, 44(4), 625-645. http://dx.doi.org/10.1111/j.1540-6288.2009.00233.x

Backus, D., Gregory, A., \& Telmer, C. (1993). Accounting for forward rates in markets for foreign currency. Journal of Finance, 48, 1887-1908. http://dx.doi.org/10.1111/j.1540-6261.1993.tb05132.x

Bekaert, G. (1996). The time variation of risk and return in foreign exchange markets: A general equilibrium perspective. Review of Financial Studies, 9, 427-470. http://dx.doi.org/10.1093/rfs/9.2.427

Burnside, C., Han, H., Hirshleifer, D., \& Wang, Y. T. (2011). Investor overconfidence and the forward premium puzzle. Review of Economic Studies, 78, 523-558. http://dx.doi.org/10.1093/restud/rdq013

Chiang, T. C. (1988). The forward rate as a predictor of the future spot rate - A stochastic coefficient approach. Journal of Money, Credit and Banking, 20(2), 212-232. http://dx.doi.org/10.2307/1992112

Fama, E. F. (1984). Forward and spot exchange rates. Journal of Monetary Economics, 14(3), 319-338. http://dx.doi.org/10.1016/0304-3932(84)90046-1

Frenkel, J. A. (1981). Flexible exchange rates, prices, and the role of "News", lessons from the 1970's. Journal of Political Economy, 89, 665-705. http://dx.doi.org/10.1086/260998

Lustig, H., Roussanov, N., \& Verdelhan, A. (2011). Common risk factors in currency markets. Review of Financial Studies, 24, 3731-3777. http://dx.doi.org/10.1093/rfs/hhr068

Lustig, H., Roussanov, N., \& Verdelhan, A. (2014). Counter-cyclical currency risk premia. Journal of Financial Economics, 111(3), 527-553. http://dx.doi.org/10.1016/j.jfineco.2013.12.005

Sarno, L., Schneider, P., \& Wagner, C. (2012). Properties of foreign exchange risk premiums. Journal of Financial Economics, 105(2), 279-310. http://dx.doi.org/10.1016/j.jfineco.2012.01.005

Sercu, P., \& Vinaimont, T. (2006). The forward bias in the ECU: Peso risks vs. fads and fashions. Journal of Banking and Finance, 30(8), 2409-2432. http://dx.doi.org/10.1016/j.jbankfin.2005.10.001

Siegel, J. E. (1972). Risk, interest rates and the forward exchange. Quarterly Journal of Economics, 86, 303-309. http://dx.doi.org/10.2307/1880565

Verdelhan, A. (2010). A habit-based explanation of the exchange rate risk premium. Journal of Finance, 65, 123-145. http://dx.doi.org/10.1111/j.1540-6261.2009.01525.x

Wu, Y., \& Zhang, H. (1997). Forward premiums as unbiased predictors of future currency depreciation: A Non-parametric analysis. Journal of International Money and Finance, 16(4), 609-623. http://dx.doi.org/10.1016/S0261-5606(97)00022-3

Wystup, U. (2010). Foreign Exchange Symmetries. Wiley Inline Library. http://dx.doi.org/10.1002/9780470061602.eqf06005

\section{Note}

Note 1. A number of earlier studies [see, for example, Burnside et al. (2011), among others] have provided insightful analysis on the role of investor irrationality in foreign exchange markets.

\section{Copyrights}

Copyright for this article is retained by the author(s), with first publication rights granted to the journal.

This is an open-access article distributed under the terms and conditions of the Creative Commons Attribution license (http://creativecommons.org/licenses/by/3.0/). 